\title{
The costs of operating under a veil of secrecy
}

\author{
Brett R. Anderson, MD, MBA, MS
}

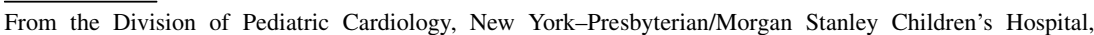 \\ Columbia University Medical Center, New York, NY. \\ B.R.A. receives salary support from the National Heart Lung and Blood Institute of the National Institutes of \\ Health (grant K23 HL133454). \\ Disclosures: Author has nothing to disclose regarding commercial support. \\ Received for publication Aug 15, 2017; accepted for publication Aug 18, 2017; available ahead of print Sept 13, \\ 2017. \\ Address for reprints: Brett R. Anderson, MD, MBA, MS, New York-Presbyterian/Morgan Stanley Children's \\ Hospital, 3959 Broadway, CH-2N, New York, NY 10032-3784 (E-mail: bra2113@ cumc.columbia.edu). \\ J Thorac Cardiovasc Surg 2017; 154:1881-2 \\ $0022-5223 / \$ 36.00$ \\ Copyright (C) 2017 by The American Association for Thoracic Surgery \\ http://dx.doi.org/10.1016/j.jtcvs.2017.08.042
}

As the United States strives to improve health care quality and curtail costs, one thing is clear: transparent cost data are needed. As novel technologies emerge on the market, it is now standard to evaluate their incremental costeffectiveness ratio - the additional cost of providing a new service divided by the change in the number of life-years (or quality-adjusted life-years [QALYs]) the new service provides. Transcatheter aortic valve replacement (TAVR) for severe aortic stenosis is no different. When the PARTNER (Placement of Aortic Transcatheter Valves) Trial was conceived, its forward-thinking investigators prospectively collected resource-based cost information for procedurerelated expenses and hospital billing data for downstream costs. TAVR was estimated to cost an additional $\$ 76,877 /$ QALY relative to surgical aortic valve replacement in high-risk patients ${ }^{1}$ and $\$ 61,889 /$ QALY relative to medical management among patients not candidates for operation ${ }^{2}$ - placing it squarely in the moderately cost-effective range. ${ }^{3}$

In this issue of the Journal, McCarthy and colleagues ${ }^{4}$ explain how incremental cost-effectiveness ratios are important from a societal perspective yet offer little insight into financial considerations facing providers and payers and influencing treatment adoption. McCarthy and colleagues ${ }^{4}$ set out to compare hospital marginal profits (revenue minus expenses) for TAVR versus surgical aortic valve replacement in propensity-matched cohorts. They defined revenue as total inpatient dollars paid by Medicare (during a 1-year time horizon) and expenses as inpatient hospital costs, derived from itemized charges and Medicare costto-charge ratios.

This is a reasonable approach—perhaps the best possible approach for data in the public domain. Readers should be clear, however, that although median cost-to-charge ratio costs (aggregated across institutions) are often used as proxies for resource use, ${ }^{5}$ they are not the true costs of providing care. Estimates presented here are not synonymous with profit. Itemized cost-to-charge ratio costs are largely fictitious, defined behind a "veil of secrecy." They are a facilities.

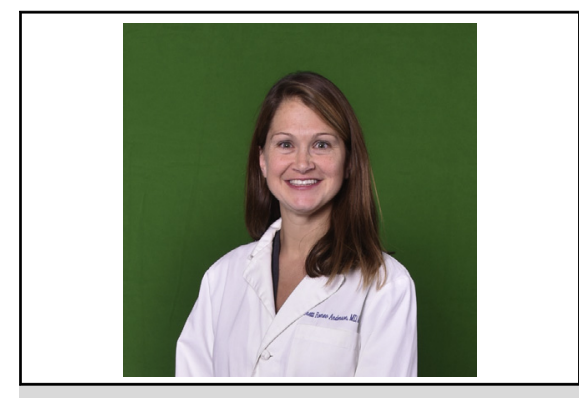

Brett R. Anderson, MD, MBA, MS

Central Message

True health care costs are largely obscured from public view. Without cost transparency, the changes necessary to influence practice, improve quality, and constrain future expenditures remain elusive.

See Article page 1872 .

function of the vagaries of individual hospital cost accounting, the byproduct of decades of cost shifting and jockeying to gain an upper hand in reimbursement negotiations and to minimize tax burdens. Each hospital defines its own "charge master," arbitrarily setting and updating prices for 20,000 to 50,000 individual billable items ${ }^{6}$; hospital charges for specific items vary by as much as 1000 -fold.

The data presented by McCarthy and colleagues ${ }^{4}$ suggest that current hospital financial models favor surgical aortic valve replacement (except where TAVR is accepted as a loss leader). Further, and critically, McCarthy and colleagues ${ }^{4}$ suggest that these differences are driven largely by the currently high cost of transcatheter devices (\$30,000 vs approximately $\$ 5,000$ for a standard surgical valve $^{1}$ ) and frequent transfer penalties incurred by patients undergoing TAVR as the result of systematic shorter lengths of stay and more rapid transition to lower-skilled care

As a society, we should incentivize-not penalizetreatments that shorten lengths of stay. Changes in the current reimbursement model, at least in the short run, might be necessary to accomplish this. One could hope, then, as TAVR use expands, more competitors will enter the device market, driving down costs. This theoretically could allow payers (such as Medicare) to reduce future TAVR payments, driving down the incremental cost-effectiveness ratio without pushing providers out of the market. McCarthy and colleagues' work $^{4}$ provides us with a window into the problem. Without cost transparency, 
however, one can only guess at the change necessary to shift practice, improve quality, and rein in expenditures.

\section{References}

1. Reynolds MR, Magnuson EA, Lei Y, Wang K, Vilain K, Li H, et al; PARTNER Investigators. Cost-effectiveness of transcatheter aortic valve replacement compared with surgical aortic valve replacement in high-risk patients with severe aortic stenosis: results of the PARTNER (Placement of Aortic Transcatheter Valves) trial (Cohort A). J Am Coll Cardiol. 2012;60:2683-92.

2. Reynolds MR, Magnuson EA, Wang K, Lei Y, Vilain K, Walczak J, et al; PARTNER Investigators. Cost-effectiveness of transcatheter aortic valve replacement compared with standard care among inoperable patients with severe aortic stenosis: results from the Placement of Aortic Transcatheter Valves (PARTNER) trial (Cohort B). Circulation. 2012;125:1102-9.
3. Neumann PJ, Cohen JT, Weinstein MC. Updating cost-effectiveness-the curious resilience of the \$50,000-per-QALY threshold. N Engl J Med. 2014; 371:796-7.

4. McCarthy FH, Savino DC, Brown CR, Bavaria JE, Kini V, Spragan DD, et al. Cost and contribution margin of transcatheter versus surgical aortic valve replacement. J Thorac Cardiovasc Surg. 2017:154:1872-80.

5. Keren R, Luan X, Localio R, Hall M, McLeod L, Dai D, et al. Pediatric Research in Inpatient Settings (PRIS) Network. Prioritization of comparative effectiveness research topics in hospital pediatrics. Arch Pediatr Adolesc Med. 2012;166: 1155-64.

6. Reinhardt UE. The pricing of U.S. hospital services: chaos behind a veil of secrecy. Health Aff (Millwood). 2006;25:57-69.

7. Hsia RY, Akosa Antwi Y, Nath JB. Variation in charges for 10 common blood tests in California hospitals: a cross-sectional analysis. BMJ Open. 2014;4: e005482. 